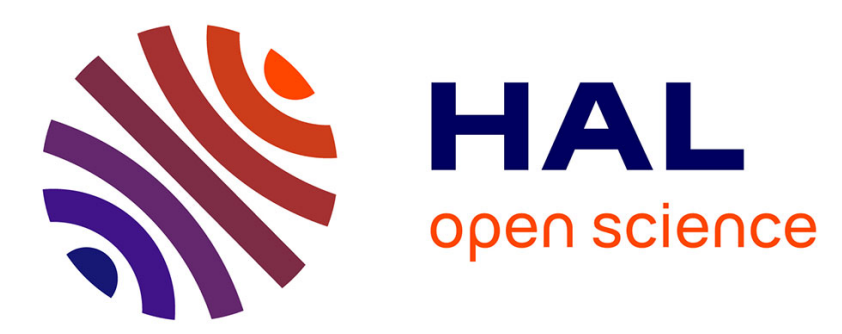

\title{
Effects of subthalamic nucleus stimulation and levodopa on decision-making in Parkinson's disease
}

Cyril Atkinson-clement, Émilie Cavazzini, Alexandre Zénon, Tatiana Witjas, Frédérique Fluchère, Jean-philippe Azulay, Christelle Baunez, Alexandre Eusebio

\section{To cite this version:}

Cyril Atkinson-clement, Émilie Cavazzini, Alexandre Zénon, Tatiana Witjas, Frédérique Fluchère, et al.. Effects of subthalamic nucleus stimulation and levodopa on decision-making in Parkinson's disease. Movement Disorders, 2019, 34 (3), pp.377-385. 10.1002/mds.27625 . hal-02327359

\section{HAL Id: hal-02327359 \\ https://hal.science/hal-02327359}

Submitted on 4 Jan 2021

HAL is a multi-disciplinary open access archive for the deposit and dissemination of scientific research documents, whether they are published or not. The documents may come from teaching and research institutions in France or abroad, or from public or private research centers.
L'archive ouverte pluridisciplinaire HAL, est destinée au dépôt et à la diffusion de documents scientifiques de niveau recherche, publiés ou non, émanant des établissements d'enseignement et de recherche français ou étrangers, des laboratoires publics ou privés. 
Effects of subthalamic nucleus stimulation and Levodopa on decision making in Parkinson's disease

Cyril Atkinson-Clement, MSc, Ph. $D^{1,2}$, Émilie Cavazzini, $M{ }^{1}{ }^{1}$, Alexandre Zénon, MSc Ph. ${ }^{3,4}$, Tatiana Witjas, MD, Ph. $D^{2,5}$, Frédérique Fluchère, MD, Ph. $D^{5,6}$, Jean-Philippe Azulay, $M D, P h . D^{2,5}$, Christelle Baunez, MSc, Ph. $D^{2}$, Alexandre Eusebio, MD, Ph.D 2,5

1 Aix Marseille Univ, CNRS, LPL, Aix-en-Provence, France.

2 Aix Marseille Univ, CNRS, INT, Inst Neurosci Timone, Marseille, France.

3 Institute of Neuroscience, Université Catholique de Louvain, 1200 Brussels, Belgium.

4 INCIA, Université de Bordeaux, CNRS UMR5287, 33076 Bordeaux, France.

5 Aix Marseille Univ, APHM, CHU Timone, Department of Neurology and Movement Disorders, Marseille, France.

6 Aix Marseille Univ, CNRS, LNC, Marseille, France.

\section{Corresponding author:}

Cyril Atkinson-Clement, MSc, Ph.D

Đcyril.atkinson-clement@lpl-aix.fr

Laboratoire Parole et Langage (LPL)

UMR 7309 - CNRS / Aix Marseille Univ

5 avenue Pasteur

13100 Aix-en-Provence, France

Word count: 3,692 (excluding Abstract and References)

Abstract word count: 250

Running title: Effects of PD treatments on motivation

Keywords: Basal ganglia; Deep brain stimulation; Dopamine; Cost-benefit; Effort

\section{Financial disclosure $\&$ competing interests}

This study was sponsored by Assistance Publique - Hôpitaux de Marseille and funded by the Agence Nationale de la Recherche (France, ANR-09-MNPS-028-01). C. Atkinson-Clement received a PhD grant funded by the PACA Regional Council and Orthomalin. The authors have no financial involvement with any organization or entity with a financial interest or conflict with the subject matter or materials discussed in the manuscript apart from those disclosed. 


\begin{abstract}
Background: Parkinson's disease is frequently associated with behavioral disorders, particularly within the spectrum of motivated behaviors such as apathy or impulsivity. Both pharmacological and neurosurgical treatments have an impact on these impairments. However, there still is controversy as to whether subthalamic nucleus deep brain stimulation can cause or reduce impulsive behaviors. In this study, we aimed to identify the influence of functional surgery on decision-making processes in Parkinson's disease.
\end{abstract}

Methods: We studied 13 Parkinson's disease patients and 13 healthy controls. The experimental task involved squeezing a dynamometer with variable force to obtain rewards of various values under 4 conditions: without treatment, with levodopa or subthalamic stimulation alone and with both levodopa and subthalamic stimulation. Statistical analyses consisted of generalized linear mixed models including treatment condition, reward value, level of effort and their interactions. We analyzed acceptance rate (the percentage of accepted trials), decision time and force applied.

Results: Comparatively to controls, patients without treatment exhibited lower acceptance rate and force applied. Patients under levodopa alone did not exhibit increased acceptance rate. With subthalamic stimulation, either with or without added levodopa, all measures were improved so that patients' behaviors were undistinguishable from healthy controls'.

Conclusions: Our study shows that levodopa administration does not fully restore cost-benefit decision-making processes, while subthalamic nucleus stimulation fully normalizes patients' behaviors. These findings suggest that dopamine is partly involved in cost-benefit valuation, and that subthalamic nucleus stimulation can have a beneficial effect on motivated behaviors in Parkinson's disease, and may improve certain forms of impulsive behaviors. 


\section{Introduction}

Idiopathic Parkinson's disease (PD) is a neurodegenerative disorder entailing several dopaminergic dysfunctions in its early stages, leading to rest tremor, akinesia and rigidity[1], but also to dysfunction in the affective and motivational processes such as depression, apathy or anhedonia (for review:[2]). Dopamine replacement therapy and, in more advanced PD, high frequency deep brain stimulation (DBS; particularly in the subthalamic nucleus [STN]) are both very effective at reducing motor symptoms. However, it is now well admitted that these treatments also impact motivated behaviors. In PD, levodopa can induce a hyperdopaminergic state that can affect decision-making processes. However, the exact effects of levodopa on decision-making are still unclear. Indeed, experimental data suggest that levodopa can impair (e.g. by increasing impulsive activation of muscles[4]), improve (e.g. by increasing response inhibition[5]) or not influence (e.g.[6]) cognitive processes involved in decisionmaking as well as inhibitory processes. According to computational models of decision-making, a hyperdopaminergic state could lead to failure of the cognitive processes involved in decisionmaking[7]. Clinically, it seems that levodopa could induce a failure of decision-making processes (i.e. by inducing impulse control disorders), even if this effect is stronger with dopamine agonists[8].

STN is a key structure of basal ganglia, involved in motor control, but also in cognitive and emotional processes. STN-DBS improves the motor symptomatology of PD, but could lead to alterations of decision-making processes. The computational function of STN in decision-making has been modeled as a structure involved in slowing down decision processes, particularly in a situation of conflict, to give the system enough time to choose the best response, giving an inhibitor role to the STN (reactive[9] and proactive[10] hypotheses; for review:[11]). In addition, we have recently shown that the STN was involved in effort-based decision-making, particularly in cost-benefit valuation processes[12]. However, this data did not prove causality as it only provided correlative evidence. Our aim was therefore to examine the impact of levodopa consumption and STN activity manipulation on decisionmaking using the same paradigm as previously[12] but involving a novel PD patients cohort and adding 
healthy participants. Establishing this is clinically relevant as there is an ongoing controversy on the effect of STN-DBS on decision-making and in particular whether or not it can cause impulsivity. Indeed, while some previous studies have reported an impairment of decision-making (through action impulsivity) after STN-DBS[13,14], others have shown improvement (for choice impulsivity)[15-18]. Here we hypothesize the following: $1 \backslash$ PD patients (without levodopa) are less motivated to perform an effort-based decision-making task, $2 \backslash$ levodopa increases that motivation, and $3 \backslash$ STN-DBS modifies cost-benefit valuation.

\section{Methods}

\section{Patients}

Seventeen idiopathic PD patients operated for STN-DBS and fulfilling UK Parkinson's disease Brain Bank Criteria[19] for the diagnosis of idiopathic PD, were recruited in the Department of Neurology and Movement Disorders of La Timone University Hospital, after providing written informed consent. The surgical procedure of electrode implantation was as previously described[20]. The stimulation electrodes were the Medtronic model 3389 with 4 plots, $1.27 \mathrm{~mm}$ in diameter and $1.5 \mathrm{~mm}$ in height, separated by insulating bands $0.5 \mathrm{~mm}$ in height. Only 13 patients performed the entire experiment, the four others were excluded for clinical reasons (e.g., excessive motor impairment preventing task performance; difficulty in understanding instructions). Clinical characteristics of the patients and STNDBS parameters are provided in Table 1. In a second step, 13 age and gender matched healthy controls were recruited. This project was approved by the local ethics committee and realized in compliance with the national legislation and the Declaration of Helsinki[21].

[TABLE.1]

All participants were screened, under medication and STN-DBS turned On, for depression (Beck Depression Inventory [BDI;[22]]; Montgomery-Asberg Depression Rating Scale [MADRS;[23]]), anxiety

(Hamilton Anxiety Rating Scale [HAM-A;[24]]), apathy (Lille Apathy Rating Scale [LARS;[25]]), 
impulsivity (Minnesota Impulsive Disorders Interview [MIDI;[26]]), cognition (Mattis Dementia Rating Scale [MDRS;[27]]) and quality of life (Parkinson's Disease Questionnaire-39 [PDQ-39;[28]]). Motor impairment was assessed under four treatment conditions (without treatment [Off DBS/Off Dopa], with levodopa alone [Off DBS/On Dopa], with STN-DBS alone [On DBS/Off Dopa], with both [On DBS/On Dopa]) using Unified Parkinson's Disease Rating Scale part-III (UPDRS-III;[29]). Demographics and clinical data are available in Table 2.

[TABLE.2]

\section{Task}

The patients were instructed to squeeze a dynamometer with variable force (12 levels) and with promise of a variable virtual monetary reward $(5 c, 20 c, 100 c)$. First, a fixation cross was displayed for 500-1500ms. Then, the reward cue was displayed, indicating the reward value. The second cue indicated the level of force needed for the current trial and was represented as a vertical gauge with a horizontal bar indicating the level required, hereafter called the threshold. When the second cue appeared, the patients had to decide whether they accepted the trial. They were instructed to decide whether or not the promised reward was worth performing the required effort.

In case they accepted, they had to start pressing the dynamometer, then the level in the gauge raised with a speed proportional to the force applied to the dynamometer. The speed was computed so that filling the gauge completely required exerting a force equal to the maximal voluntary contraction force (MVC) for 7.6s. The 12 levels used were $0.5,0.725,0.95,1.0,1.45,1.9,2.0,2.9,3.8,4.0,5.8,7.6 \mathrm{~s}$ at MVC (corresponding to the integral of exerted force over time), although, as noted above, subjects were free to vary how these effort levels were achieved by trading duration for force. The MVC was measured at the beginning of each block and the force levels adapted accordingly to adjust for fatigue. After the level indicated on the gauge reached the threshold, a fixation cross was displayed for 500$1500 \mathrm{~ms}$, followed by the reward feedback, accompanied by a bell sound with the sentence "You win", 
shown on the screen for 2000ms (Fig.1). Any squeezing of the bulb before the effort cue onset stopped the trial.

When the patients wished to refuse the proposed trial, they had to withhold their response for $4 \mathrm{~s}$, then a display of the reward amount they had refused was shown superimposed with a red crossed on the screen for $2000 \mathrm{~ms}$. Intercue intervals were randomized so as to limit the expectation of the upcoming cue and any related preparation. Each of the 36 conditions ( 3 reward $x 12$ force) were equal and they were presented in randomized order. Due to time constraints, only the participant's dominant hand performed the grip task.

[FIGURE.1]

\section{Procedure}

After the patients were seated, they first had to perform three MVC by squeezing the pressure bulb as hard as possible for effort adjustments during the following block. They received vocal encouragements during this exercise. Patients were then trained on the task with a slowed-down version in which a break was added between each phase, allowing the experimenter to explain the meaning of each phase of the task and the responses that were expected from them. Then, each patient performed four $8 \mathrm{~min}$ blocks of the task On and Off STN-DBS, with a total of $128 \mathrm{~min}$ over two half-days (one half-day On levodopa, the other Off levodopa). The treatment conditions were applied in a pseudo-randomized order to decrease the influence of repetition, habituation or fatigue caused by the task. Each block included an average of $30.8 \pm 2.6$ trials. The Off levodopa sessions were realized after an overnight (12hours) withdrawal of treatment[30]. The On levodopa sessions were undertaken 45-60min after the intake of a unique levodopa dose corresponding to $150 \%$ of each patient's morning dose. Efficacy of the levodopa administration in the ON-drug state was assessed using the UPDRS-III score about 45min after ingestion of levodopa. All patients felt at "best On" and improved their UPDRSIII score by $68.1 \% \pm 13.3 \%$ compared with the Off-drug state $(t=7.47, p<0.001)$. The Off/On STN-DBS sessions were undertaken at least $20 \mathrm{~min}$ after STN-DBS switched Off/On as about $75 \%$ of the UPDRS- 
III score decrease occurs within this time frame following discontinuation of DBS[31]. For example, during the first day, a patient performed one session without any treatment ( 4 blocks) followed by one session with active STN-DBS (4 blocks), while during the second day, he did one session with both levodopa and active STN-DBS (4 blocks) followed by one session under levodopa alone (4 blocks).

\section{Statistical analyses}

All statistical analyses were conducted with $\mathrm{R}$ [32] and SAS software[33]. Clinical and demographic comparisons consisted of non-parametric statistics (Kruskal-Wallis). For other variables, we ran Generalized Linear Mixed Models (GLMM). The model included systematically treatment condition (Off DBS/Off Dopa; Off DBS/On Dopa; On DBS/Off Dopa; On DBS/On Dopa; HC), reward cue value (5c; 20c; 100c), effort cue value (from 1 to 12 ) and all their interactions. Participants were included as random effects, taking into account the between-subject variations of intercepts and all fixed effect slopes. Moreover, the association between each patient and his matched healthy control were included in our analyses. Three variables were analyzed: the acceptance rate which corresponds to the percentage of accepted trials (logit), the decision time (Gaussian) and the time to complete each item (log; equivalent to the exerted force). The acceptance rate corresponds to the successful trials and tried but failed trials divided by the total number of trials. Lastly, we performed Sidak's adjustment for multiple comparisons between $\mathrm{HC}$ and all PD treatments conditions (to identifying how PD states are different from a "normal" behavior) and between Off DBS/Off Dopa condition and the three other treatments conditions (to identifying how treatments modify patient's behavior).

\section{Results}

\section{Demographic and clinical results}

We compared PD and HC as for demographic and clinical data. We found no significant difference in age, validating the matching of our groups. Regarding clinical data, we found differences between PD 
patients and $\mathrm{HC}$ for several assessments, corresponding to lower scores for PD patients in the BDI $\left(\chi^{2}=9.8, p=0.001\right), \operatorname{MDRS}\left(\chi^{2}=5.5, p=0.018\right)$ and semantic fluency $\left(\chi^{2}=7.8, p=0.004\right)$. Moreover, we found an improvement of the UPDRS part-II $\left(\chi^{2}=11, p<0.001\right)$ and of the Schwab and England scale $\left(\chi^{2}=12.2\right.$, $\mathrm{p}<0.001)$ under the treatment condition compared with the without treatment condition.

\section{Acceptance rate}

As expected, the acceptance rate increased with the reward value $(F(2,24)=28.55, p<0.0001)$ and decreased with the effort required $(F(1,12)=63.66, \mathrm{p}<0.0001)$. In addition, the treatment condition had a significant effect on the acceptance rate $(F(4,48)=3.59, \mathrm{p}=0.0063)$ and we observed a significant interaction between treatment condition and reward value $(F(8,96)=3.25, \mathrm{p}=0.0011)$ and magnitude of effort $(F(4,48)=2.61, \mathrm{p}=0.0334$; Fig.2.A $)$. In a second step, contrast analyses between each treatment condition revealed that patients Off DBS/Off Dopa exhibited decreased acceptance rate $(p=0.0127)$ linked both to effort $(p=0.0088)$ and to reward $(p=0.0419)$. Patients Off $D B S / O n$ Dopa also exhibited decreased acceptance rate $(p=0.0404)$ but linked only to effort $(p=0.0336)$. Similarly, patients Off DBS/Off Dopa less often agreed to execute the task than patients under STN-DBS, whether with $(p=0.0049)$ or without levodopa $(p=0.0226)$.

\section{Decision time}

The results of the GLMM on decision time revealed a significant main effect of reward value $(F(2,24)=6.04, \mathrm{p}=0.0024)$, effort magnitude $(F(1,12)=27.05, \mathrm{p}<0.0001)$ and treatment condition $(F(4,48)=2.48, p=0.0419$, Fig. $2 . B$ ) but no significant interaction (all $p>0.05$ ). Contrasts between treatment conditions revealed only one significant difference, namely an increase in decision time for the patients Off DBS/On Dopa when compared with the HC group ( $p=0.0374)$.

\section{Time to complete}


The time taken to complete a trial corresponded to the reciprocal of the average force exerted on the dynamometer. The longer the time, the lower the exerted force. As expected, the GLMM analysis revealed an effect of the effort $(F(1,12)=397.75, p<0.0001)$, but also a significant effect of the treatment condition $(F(4,48)=2.51, \mathrm{p}=0.0397)$ and an interaction between effort magnitude and treatment condition $(F(4,48)=2.72, p=0.028)$. Contrast analyses revealed a significant increase in the time to complete each trial for patients under the Off DBS/Off Dopa condition comparatively to HC $(p=0.0185)$, patients under the On DBS/On Dopa $(p=0.007)$ and On DBS/Off Dopa conditions $(p=0.0318)$. For the interaction between treatment condition and effort level, we observed significant differences between the HC group (intercept=7.53; slope=0.146) and patients under the Off DBS/Off Dopa (intercept=7.805; slope=0.113; $p=0.01$ ) and Off DBS/On Dopa conditions (intercept=7.703; slope=0.104; $p=0.008 ;$ Fig.2.C).

\section{[FIGURE.2]}

\section{Discussion}

The present study is, to the best of our knowledge, the first to explore the effects of both levodopa and STN-DBS on effort and reward-based decision-making in PD patients. Our data revealed three major findings. First, PD patients Off treatment exhibited a decrease in the acceptance rate and force applied when compared with controls. Second, we observed no difference between HC and patients under STN-DBS. Third, interestingly no significant effect of levodopa was found on acceptance rate alone or combined with STN-DBS.

Consistent with our first hypothesis, the first outcome of the present study is that patients without treatment exhibited a decrease in their acceptance rate and their exerted force compared with $\mathrm{HC}$. These results represent a significant contribution to our previous study using the same task, but without comparison with $\mathrm{HC}[12]$. These results are partly in line with the report of decreased acceptance rate for low rewards mentioned in a previous study assessing effort-based decision-making 
in PD patients without treatment comparatively to $\mathrm{HC}[34]$. However, we observed here a decrease in acceptance rate related to rewards and efforts and a decrease in exerted force, which can be interpreted as a general decrease in motivation induced by PD. This reinforces the hypothesis that striatal dysfunction induces a decrease in the motivation to exert an action to obtain a reward. This may indicate that PD modifies the cost-benefit valuation, by decreasing the value of a reward and increasing the cost of an effort. In fact, a part of the scientific literature suggests that the mesolimbic system could be involved in reward valuation (e.g. inducing an aberrant focus on reward-driven activities[36] and contributing deciding to engage in an effortful task for a reward[37]), while the mesocortical system could be involved in effort processing (e.g. contributing to decide how difficult is an action in a specific context[38] and implying in effort learning signal[39]), both impaired in PD[40]. Consequently, it is reasonable to propose that the impairment of these two non-motor networks could contribute to the decreased vigor in movements executed by PD patients without treatment.

Then, we tested the hypothesis whether levodopa could improve these impairments of decisionmaking. We observed a normalization (in comparison to $\mathrm{HC}$ ) of the exerted force, most likely due to motor improvement under levodopa. Surprisingly, no difference was observed between Off and On levodopa conditions on the acceptance rate, invalidating our second hypothesis. On the one hand, some evidence from both human and animal studies suggests that dopamine is involved in decisionmaking processes, and especially on the exertion of an effort to obtain a reward[12,34,41,42]. In this context, the effects of levodopa can be interpreted as a correction of the motivational deficit induced by striatal dysfunction[34]. On the other hand, some studies suggest that dopamine only has a partial influence on decision-making, and more precisely that dopamine would have an effect on reward sensitivity but not on other parameters involved in effort-based decision-making processes[43,44]. This may support the fact that, in our task, dopamine had a limited effect on effort cost representation, but was involved in the modulation of how much effort a given reward is worth[44]. In fact, levodopa 
partially corrected the deficit by only restoring the acceptance rate based on reward representations (but not on representations of effort) while restoring the motor capacity to produce a normal level effort. Taken together, these results may suggest that levodopa is involved in reward valuation[39] and restores the capacity to produce an effort to normal levels but patients remain reluctant to exert highlevel efforts. This suggests that levodopa remained insufficient for cost-benefit computation in the present task, indicating that the motivation deficits observed in PD patients cannot be explained only by a lack of dopamine. However, it is still possible that the absence of levodopa effects could be artefactual. More precisely, we can hypothesize that the levodopa dose (150\% of each patient's morning dose), as well as the short duration between the levodopa consumption and the participation to our task, were not sufficient to provide full dopaminergic restoration.

Lastly, similar acceptance rates, decision time and exerted force between PD patients under DBS (with and without levodopa) and $\mathrm{HC}$ were found. This is in agreement with our third hypothesis, addressing that STN-DBS induces a modification of cost-benefit valuation in PD. Two main interpretations could contribute to explain this outcome. First, we can suggest that STN-DBS induces a deregulation of costbenefit valuation processes in contexts involving a significant cognitive cost, such as a cognitive conflict $[9,45]$ or under speed pressure[46]. A recent study found no effect of STN-DBS in the absence of conflict, time pressure or anticipation[48]. These findings could explain the results variability of the scientific literature according to experimental tasks[49,50], probably related to different mechanisms and explaining the ongoing controversy about the role of STN-DBS on impulsivity. To some extent, impulsivity should be fragmented: ilmpulsivity of action, often measured with precocious responding, is increased after STN-DBS[51]; while impulsivity of choice, assessed using delay-discounting tasks[52], risky and ambiguous choices[53], or even gambling tasks[54] can be reduced after STN-DBS. Even though our experimental task can lead to cognitive conflicts[12], we suggest that the degree of conflict is not sufficient to observe a deregulation of cost-benefit valuation, and that our task is more related 
to choice impulsivity rather than action impulsivity. Secondly, we can interpret our results as a normalization of decision-making processes under STN-DBS, as previously observed for extreme decision-making disorders like inhibition impairment (for a review:[55]), dopamine dysregulation syndrome[15] or more generally for hyperdopaminergic behaviors and neuropsychiatric disorders $[16,18]$. An additional argument could be also the fact that STN-DBS is known to improve PD patients with impulsive-compulsive behaviors[15,18,56,57]. Regarding potential neural mechanisms, we hypothesize that STN-DBS normalizes the integration of reward value signals from the orbitofrontal cortex[60] and effort inputs from the anterior cingulate, insula and supplementary motor area[61,62]. This would lead to a normalization of cost-benefit valuation[12] and control of the attribution of a motor effort required for a response[64]. Nevertheless, STN-DBS is frequently associated with a reduction of levodopa consumption, making it more difficult to conclude about the direct effect of functional neurosurgery. However, one recent study reported a decrease in impulsive behavior in PD patients after STN-DBS or Globus Pallidus internus DBS without any reduction in medication consumption, concluding that the improvement of motivated behaviors is due to the effect of DBS alone or combined with levodopa, but not to the sole reduction in medication consumption[56].

With a similar experimental paradigm used previously[12,34] and results somewhat different, our study also questions the possibility of long-term neuroplastic reorganization mechanisms following STN-DBS[69]. This would explain why the effect of levodopa in decision-making is different before and after STN-DBS. Actually, some studies observed a reduced psychostimulant effect of levodopa under STN-DBS, resulting from striatum desensitization due to the reduction of dopaminergic consumption[70]. In addition, DBS leads to a decrease in beta band power after 6 and 12 months, independently of electrical stimulation parameters, and this decrease correlates with motor UPDRS improvement[71]. These results underlie that long-term STN-DBS induces plasticity in the sensorimotor pathway. Therefore, because of such plasticity, our results may be different from those 
previously obtained, which considered PD patients without DBS[34] or with a short delay after surgery[12].

\section{Limitations}

We acknowledge that several limitations in our study have to be addressed. The use of fictive monetary rewards may be considered a limitation although it has been successfully used in previous similar experiments[12,34,43,72]. Neuroimaging studies revealed that real and fictive rewards recruit overlapping neural networks[73], suggesting that our results could be reasonably extrapolated to a situation involving a real reward. Also, even if a previous study using a comparable task showed that levodopa on motor improvement was not involved in decision-making[34], several other studies observed that STN-DBS could induce an improvement of maximal voluntary contraction [74], could improve the regulation of force levels [75] and that STN local field potentials of the STN are modulated in patients who generated different levels of isometric force [76]. Thus, it is possible to suggest that our findings may be partly attributable to motor improvement due to levodopa and/or STN-DBS. Moreover, the relatively small number of participants for the amount of conditions studied as well as the large inter- and intra-variability of the measures constitutes a limitation of this study, although several comparable studies were performed with a similar number of participants $[12,48,50,77]$. To partly overcome this situation, we chose to use GLMM, allowing stringent statistical analysis and reinforcing the robustness of our significant results. However, this approach may have lead us to miss some differences between groups. For example, as shown in Fig.2.B, levodopa significantly increases decision time. Whether this reflects a specific effect of levodopa or rather an uncorrected effect of the disease itself could not be established here. Also, we reported significant differences between PD patients and HC for cognitive (MDRS and semantic fluency) and mood (BDI) assessments. We cannot exclude that these differences could contribute to our results. However, the patients' scores did not reach the threshold of cognitive impairments and depression. Lastly, the delay of 20min after STN-DBS 
was switched on/off could be insufficient, in so far as some STN-DBS non-motor effects may appear/disappear after a period of several minutes, hours or even days. As STN-DBS effects evolve quickly and resolve slowly, we cannot exclude that the Off STN-DBS condition does not perfectly correspond to an Off state.

\section{Conclusion}

Our findings show that PD alters effort-based decision-making processes, and that levodopa did not fully restore these processes. Only high frequency STN-DBS, with or without levodopa, seemed to normalize cost-benefit valuation in our task. We hypothesize that STN-DBS could help restoring the integration of input from cortical territories in relation to reward and effort valuation. Furthermore, our study suggests that some aspects of decision-making disorders like impulsive behaviors may be improved by STN-DBS, contributing to the controversy around DBS-induced impulsivity.

\section{Acknowledgements}

We are thankful to Patrick Rossi, Laura Mundler, Pr. Jean-Marie Régis and Dr. Romain Carron for their implication during the realization of this study. The authors would like to thank Ms. Mignard for her helpful revision of the English of the article.

\section{Authors' roles}

1. Research Project: A. Conception, B. Organization, C. Execution;

2. Statistical Analysis: A. Design, B. Execution, C. Review and Critique;

3. Manuscript Preparation: A. Writing the First Draft, B. Review and Critique.

C.A-C.: 1B, 1C, 2A, 2B, 3A, 3B

E.C.: $1 C, 2 C, 3 B$

A.Z.: $1 \mathrm{~A}, 1 \mathrm{~B}, 2 \mathrm{~A}, 2 \mathrm{~B}, 2 \mathrm{C}, 3 \mathrm{~B}$ 
T.W.: 1C, 3B

F.F.: 1C, 3B

J-F.A.: 1C, 3B

C.B.: $2 \mathrm{C}, 3 \mathrm{~B}$

A.E.: 1A, 1B, 1C, 2C, 3B

\section{References}

1. Marsden CD. Parkinson's disease. J Neurol Neurosurg Psychiatry. 1994;57:672-81.

2. Kaji Y, Hirata K. Apathy and anhedonia in Parkinson's disease. ISRN Neurol.

2011;2011:219427:219427.

3. Poletti M, Logi C, Lucetti C, Del Dotto P, Baldacci F, Vergallo A, et al. A Single-Center, CrossSectional Prevalence Study of Impulse Control Disorders in Parkinson Disease: Association With Dopaminergic Drugs. J Clin Psychopharmacol. 2013;33:691-4.

4. Fluchère $F$, Deveaux $M$, Burle $B$, Vidal $F$, van den Wildenberg WPM, Witjas $T$, et al. Dopa therapy and action impulsivity: subthreshold error activation and suppression in Parkinson's disease. Psychopharmacology (Berl). 2015;232:1735-46.

5. Manza P, Schwartz G, Masson M, Kann S, Volkow ND, Li CR, et al. Levodopa improves response inhibition and enhances striatal activation in early-stage Parkinson's disease. Neurobiol Aging.

2018;66:12-22.

6. Obeso I, Wilkinson L, Jahanshahi M. Levodopa medication does not influence motor inhibition or conflict resolution in a conditional stop-signal task in Parkinson's disease. Exp Brain Res.

2011;213:435-45.

7. Frank MJ. By Carrot or by Stick: Cognitive Reinforcement Learning in Parkinsonism. Science. 2004;306:1940-3.

8. Weintraub D, Koester J, Potenza MN, Siderowf AD, Stacy M, Voon V, et al. Impulse Control Disorders in Parkinson Disease: A Cross-Sectional Study of 3090 Patients. Arch Neurol. 2010;67:58995.

9. Frank MJ, Samanta J, Moustafa AA, Sherman SJ. Hold your horses: impulsivity, deep brain stimulation, and medication in parkinsonism. Science. 2007;318:1309-12.

10. Ballanger B, van Eimeren T, Moro E, Lozano AM, Hamani C, Boulinguez $P$, et al. Stimulation of the subthalamic nucleus and impulsivity: Release your horses. Ann Neurol. 2009;66:817-24.

11. Jahanshahi M, Obeso I, Rothwell JC, Obeso JA. A fronto-striato-subthalamic-pallidal network for goal-directed and habitual inhibition. Nat Rev Neurosci. 2015;16:719-32. 
12. Zénon A, Duclos Y, Carron R, Witjas T, Baunez C, Régis J, et al. The human subthalamic nucleus encodes the subjective value of reward and the cost of effort during decision-making. Brain. 2016;139:1830-43.

13. Cavanagh JF, Wiecki TV, Cohen MX, Figueroa CM, Samanta J, Sherman SJ, et al. Subthalamic nucleus stimulation reverses mediofrontal influence over decision threshold. Nat Neurosci. 2011;14:1462-7.

14. Coulthard EJ, Bogacz R, Javed S, Mooney LK, Murphy G, Keeley S, et al. Distinct roles of dopamine and subthalamic nucleus in learning and probabilistic decision making. Brain. 2012;135:3721-34.

15. Eusebio A, Witjas T, Cohen J, Fluchere F, Jouve E, Regis J, et al. Subthalamic nucleus stimulation and compulsive use of dopaminergic medication in Parkinson's disease. J Neurol Neurosurg Psychiatry. 2013;84:868-74.

16. Lhommee $E$, Klinger $H$, Thobois $S$, Schmitt $E$, Ardouin $C$, Bichon A, et al. Subthalamic stimulation in Parkinson's disease: restoring the balance of motivated behaviours. Brain. 2012;135:1463-77.

17. Witjas T, Baunez C, Henry JM, Delfini M, Regis J, Cherif AA, et al. Addiction in Parkinson's disease: Impact of subthalamic nucleus deep brain stimulation. Mov Disord. 2005;20:1052-5.

18. Lhommée E, Wojtecki L, Czernecki V, Witt K, Maier F, Tonder L, et al. Behavioural outcomes of subthalamic stimulation and medical therapy versus medical therapy alone for Parkinson's disease with early motor complications (EARLYSTIM trial): secondary analysis of an open-label randomised trial. Lancet Neurol. 2018;17:223-31.

19. Gibb WR, Lees AJ. A comparison of clinical and pathological features of young- and old-onset Parkinson's disease. Neurology. 1988;38:1402-6.

20. Fluchere F, Witjas T, Eusebio A, Bruder N, Giorgi R, Leveque M, et al. Controlled general anaesthesia for subthalamic nucleus stimulation in Parkinson's disease. J Neurol Neurosurg Psychiatry. 2014;85:1167-73.

21. World Medical Association General Assembly. Declaration of Helsinki, Amendment. 2004.

22. Beck AT, Beck RW. Screening depressed patients in family practice. A rapid technic. Postgrad Med. 1972;52:81-5.

23. Montgomery SA, Asberg M. A new depression scale designed to be sensitive to change. $\mathrm{Br} \mathrm{J}$ Psychiatry J Ment Sci. 1979;134:382-9.

24. Hamilton M. The assessment of anxiety states by rating. Br J Med Psychol. 1959;32:50-5.

25. Sockeel P, Dujardin K, Devos D, Denève C, Destée A, Defebvre L. The Lille apathy rating scale (LARS), a new instrument for detecting and quantifying apathy: validation in Parkinson's disease. J Neurol Neurosurg Psychiatry. 2006;77:579-84.

26. Christenson GA, Faber RJ, de Zwaan M, Raymond NC, Specker SM, Ekern MD, et al. Compulsive buying: descriptive characteristics and psychiatric comorbidity. J Clin Psychiatry. 1994;55:5-11.

27. Mattis $S$. Mental status examination for organic mental syndrome in the elderly patients. Geriatr Psychiatry Handb Psychiatr Prim Care Physicians. Bellak L, Karasu T (eds); 1976. p. 77-121. 
28. Jenkinson C, Fitzpatrick R, Peto V, Greenhall R, Hyman N. The Parkinson's Disease Questionnaire (PDQ-39): development and validation of a Parkinson's disease summary index score. Age Ageing. 1997;26:353-7.

29. Fahn S, Elton R, Members of the UPDRS Development Committee. Recent developments in Parkinson's Disease. Florham Park: Macmillan Health Care Information; 1987.

30. Langston JW, Widner H, Goetz CG, Brooks D, Fahn S, Freeman T, et al. Core assessment program for intracerebral transplantations (CAPIT). Mov Disord. 1992;7:2-13.

31. Temperli P, Ghika J, Villemure J-G, Burkhard PR, Bogousslavsky J, Vingerhoets FJG. How do parkinsonian signs return after discontinuation of subthalamic DBS? Neurology. 2003;60:78-81.

32. $\mathrm{R}$ Core Team. R: A language and environment for statistical computing [Internet]. Vienna, Austria: R Foundation for Statistical Computing; 2013. Available from: http://www.R-project.org/

33. SAS Institute Inc. SAS 9.3 Help and Documentation. Cary, NC: SAS Institute Inc.; 2011.

34. Chong TT-J, Bonnelle V, Manohar S, Veromann K-R, Muhammed K, Tofaris GK, et al. Dopamine enhances willingness to exert effort for reward in Parkinson's disease. Cortex. 2015;69:40-6.

35. Pagonabarraga J, Kulisevsky J. Apathy in Parkinson's Disease. Int Rev Neurobiol [Internet]. Elsevier; 2017 [cited 2017 Nov 5]. p. 657-78. Available from:

http://linkinghub.elsevier.com/retrieve/pii/S007477421730082X

36. Stark AJ, Smith CT, Lin Y-C, Petersen KJ, Trujillo P, van Wouwe NC, et al. Nigrostriatal and Mesolimbic D2/3 Receptor Expression in Parkinson's Disease Patients with Compulsive RewardDriven Behaviors. J Neurosci. 2018;38:3230-9.

37. Salamone JD, Correa M, Yohn S, Lopez Cruz L, San Miguel N, Alatorre L. The pharmacology of effort-related choice behavior: Dopamine, depression, and individual differences. Behav Processes. 2016;127:3-17.

38. Rudebeck PH, Walton ME, Smyth AN, Bannerman DM, Rushworth MFS. Separate neural pathways process different decision costs. Nat Neurosci. 2006;9:1161-8.

39. Hauser TU, Eldar E, Dolan RJ. Separate mesocortical and mesolimbic pathways encode effort and reward learning signals. Proc Natl Acad Sci. 2017;114:E7395-404.

40. Phillips PEM, Walton ME, Jhou TC. Calculating utility: preclinical evidence for cost-benefit analysis by mesolimbic dopamine. Psychopharmacology (Berl). 2007;191:483-95.

41. Beierholm U, Guitart-Masip M, Economides M, Chowdhury R, Düzel E, Dolan R, et al. Dopamine Modulates Reward-Related Vigor. Neuropsychopharmacology. 2013;38:1495-503.

42. Treadway MT, Buckholtz JW, Cowan RL, Woodward ND, Li R, Ansari MS, et al. Dopaminergic mechanisms of individual differences in human effort-based decision-making. J Neurosci Off J Soc Neurosci. 2012;32:6170-6.

43. Le Bouc R, Rigoux L, Schmidt L, Degos B, Welter M-L, Vidailhet M, et al. Computational Dissection of Dopamine Motor and Motivational Functions in Humans. J Neurosci. 2016;36:6623-33. 
44. Zénon A, Devesse S, Olivier E. Dopamine Manipulation Affects Response Vigor Independently of Opportunity Cost. J Neurosci Off J Soc Neurosci. 2016;36:9516-25.

45. Zavala B, Tan H, Little S, Ashkan K, Hariz M, Foltynie T, et al. Midline Frontal Cortex LowFrequency Activity Drives Subthalamic Nucleus Oscillations during Conflict. J Neurosci. 2014;34:732233.

46. Pote I, Torkamani M, Kefalopoulou Z-M, Zrinzo L, Limousin-Dowsey P, Foltynie T, et al. Subthalamic nucleus deep brain stimulation induces impulsive action when patients with Parkinson's disease act under speed pressure. Exp Brain Res. 2016;234:1837-48.

47. Zavala B, Brittain J-S, Jenkinson N, Ashkan K, Foltynie T, Limousin P, et al. Subthalamic Nucleus Local Field Potential Activity during the Eriksen Flanker Task Reveals a Novel Role for Theta Phase during Conflict Monitoring. J Neurosci. 2013;33:14758-66.

48. Leimbach F, Georgiev D, Litvak V, Antoniades C, Limousin P, Jahanshahi M, et al. Deep Brain Stimulation of the Subthalamic Nucleus Does Not Affect the Decrease of Decision Threshold during the Choice Process When There Is No Conflict, Time Pressure, or Reward. J Cogn Neurosci. 2018;1-9.

49. Graef S, Biele G, Krugel LK, Marzinzik F, Wahl M, Wotka J, et al. Differential Influence of Levodopa on Reward-Based Learning in Parkinson's Disease. Front Hum Neurosci [Internet]. 2010 [cited 2017 Jun 7];4. Available from: http://journal.frontiersin.org/article/10.3389/fnhum.2010.00169/abstract

50. Huang Y-T, Georgiev D, Foltynie T, Limousin P, Speekenbrink M, Jahanshahi M. Different effects of dopaminergic medication on perceptual decision-making in Parkinson's disease as a function of task difficulty and speed-accuracy instructions. Neuropsychologia. 2015;75:577-87.

51. Fluchère $F$, Burle $B$, Vidal $F$, van den Wildenberg $W$, Witjas $T$, Eusebio $A$, et al. Subthalamic nucleus stimulation, dopaminergic treatment and impulsivity in Parkinson's disease.

Neuropsychologia [Internet]. 2018 [cited 2018 Apr 3]; Available from:

http://linkinghub.elsevier.com/retrieve/pii/S0028393218300733

52. Winstanley CA, Baunez C, Theobald DEH, Robbins TW. Lesions to the subthalamic nucleus decrease impulsive choice but impair autoshaping in rats: the importance of the basal ganglia in Pavlovian conditioning and impulse control. Eur J Neurosci. 2005;21:3107-16.

53. Brandt J, Rogerson M, Al-Joudi H, Reckess G, Shpritz B, Umeh CC, et al. Betting on DBS: Effects of subthalamic nucleus deep brain stimulation on risk taking and decision making in patients with Parkinson's disease. Neuropsychology. 2015;29:622-31.

54. Adams WK, Vonder Haar C, Tremblay M, Cocker PJ, Silveira MM, Kaur S, et al. Deep-Brain Stimulation of the Subthalamic Nucleus Selectively Decreases Risky Choice in Risk-Preferring Rats. eneuro. 2017;4:ENEURO.0094-17.2017.

55. Jahanshahi M, Obeso I, Baunez C, Alegre M, Krack P. Parkinson's Disease, the Subthalamic Nucleus, Inhibition, and Impulsivity. Mov Disord. 2015;30:128-40.

56. Rossi PJ, De Jesus S, Hess CW, Martinez-Ramirez D, Foote KD, Gunduz A, et al. Measures of impulsivity in Parkinson's disease decrease after DBS in the setting of stable dopamine therapy. Parkinsonism Relat Disord [Internet]. 2017 [cited 2017 Oct 16]; Available from: http://linkinghub.elsevier.com/retrieve/pii/S1353802017302870 
57. Gee L, Smith H, De La Cruz P, Campbell J, Fama C, Haller J, et al. The Influence of Bilateral Subthalamic Nucleus Deep Brain Stimulation on Impulsivity and Prepulse Inhibition in Parkinson's Disease Patients. Stereotact Funct Neurosurg. 2015;93:265-70.

58. Chabardès S, Polosan M, Krack P, Bastin J, Krainik A, David O, et al. Deep Brain Stimulation for Obsessive-Compulsive Disorder: Subthalamic Nucleus Target. World Neurosurg. 2013;80:S31.e1S31.e8.

59. Mallet L, Polosan M, Jaafari N, Baup N, Welter M-L, Fontaine D, et al. Subthalamic Nucleus Stimulation in Severe Obsessive-Compulsive Disorder. N Engl J Med. 2008;359:2121-34.

60. Padoa-Schioppa C, Cai X. The orbitofrontal cortex and the computation of subjective value: consolidated concepts and new perspectives: OFC and subjective value. Ann N Y Acad Sci. 2011;1239:130-7.

61. Croxson PL, Walton ME, O’Reilly JX, Behrens TEJ, Rushworth MFS. Effort-Based Cost-Benefit Valuation and the Human Brain. J Neurosci. 2009;29:4531-41.

62. Zénon A, Sidibe M, Olivier E. Disrupting the Supplementary Motor Area Makes Physical Effort Appear Less Effortful. J Neurosci. 2015;35:8737-44.

63. Brown P, Eusebio A. Paradoxes of functional neurosurgery: Clues from basal ganglia recordings. Mov Disord. 2008;23:12-20.

64. Tan H, Pogosyan A, Ashkan K, Cheeran B, FitzGerald JJ, Green AL, et al. Subthalamic Nucleus Local Field Potential Activity Helps Encode Motor Effort Rather Than Force in Parkinsonism. J Neurosci. 2015;35:5941-9.

65. Breysse E, Pelloux Y, Baunez C. The Good and Bad Differentially Encoded within the Subthalamic Nucleus in Rats. eNeuro [Internet]. 2015 [cited 2017 Nov 5];2. Available from: http://eneuro.sfn.org/cgi/doi/10.1523/ENEURO.0014-15.2015

66. Rossi PJ, Peden C, Castellanos O, Foote KD, Gunduz A, Okun MS. The human subthalamic nucleus and globus pallidus internus differentially encode reward during action control: Encoding of Reward in the STN and GPi. Hum Brain Mapp. 2017;38:1952-64.

67. Antonelli F, Ko JH, Miyasaki J, Lang AE, Houle S, Valzania F, et al. Dopamine-agonists and impulsivity in Parkinson's disease: Impulsive choices vs. impulsive actions: Dopamine-Agonists and Impulsivity in PD. Hum Brain Mapp. 2014;35:2499-506.

68. Stevens JR. The Many Faces of Impulsivity. In: Stevens JR, editor. Impulsivity [Internet]. Cham: Springer International Publishing; 2017 [cited 2018 Jul 18]. p. 1-6. Available from: http://link.springer.com/10.1007/978-3-319-51721-6_1

69. van Hartevelt TJ, Cabral J, Deco G, Møller A, Green AL, Aziz TZ, et al. Neural Plasticity in Human Brain Connectivity: The Effects of Long Term Deep Brain Stimulation of the Subthalamic Nucleus in Parkinson's Disease. Finkelstein DI, editor. PLoS ONE. 2014;9:e86496.

70. Castrioto A, Kistner A, Klinger H, Lhommée E, Schmitt E, Fraix V, et al. Psychostimulant effect of levodopa: reversing sensitisation is possible. J Neurol Neurosurg Psychiatry. 2013;84:18-22. 
71. Trager MH, Koop MM, Velisar A, Blumenfeld Z, Nikolau JS, Quinn EJ, et al. Subthalamic beta oscillations are attenuated after withdrawal of chronic high frequency neurostimulation in Parkinson's disease. Neurobiol Dis. 2016;96:22-30.

72. Rossi PJ, Shute JB, Opri E, Molina R, Peden C, Castellanos O, et al. Impulsivity in Parkinson's disease is associated with altered subthalamic but not globus pallidus internus activity. J Neurol Neurosurg Psychiatry. 2017;88:968-70.

73. Bickel WK, Pitcock JA, Yi R, Angtuaco EJC. Congruence of BOLD Response across Intertemporal Choice Conditions: Fictive and Real Money Gains and Losses. J Neurosci. 2009;29:8839-46.

74. Vaillancourt DE, Prodoehl J, Sturman MM, Bakay RAE, Metman LV, Corcos DM. Effects of deep brain stimulation and medication on strength, bradykinesia, and electromyographic patterns of the ankle joint in Parkinson's disease. Mov Disord. 2006;21:50-8.

75. Chen CC, Lin WY, Chan HL, Hsu YT, Tu PH, Lee ST, et al. Stimulation of the subthalamic region at 20Hz slows the development of grip force in Parkinson's disease. Exp Neurol. 2011;231:91-6.

76. Florin E, Dafsari HS, Reck C, Barbe MT, Pauls KAM, Maarouf M, et al. Modulation of local field potential power of the subthalamic nucleus during isometric force generation in patients with Parkinson's disease. Neuroscience. 2013;240:106-16.

77. Fischer P, Pogosyan A, Cheeran B, Green AL, Aziz TZ, Hyam J, et al. Subthalamic nucleus beta and gamma activity is modulated depending on the level of imagined grip force. Exp Neurol.

2017;293:53-61. 


\section{Tables and figures captions}

TABLE 1. Clinical data and STN-DBS parameters of the PD patients

\begin{tabular}{|c|c|c|c|c|c|c|c|c|c|c|c|c|}
\hline \multirow[b]{2}{*}{ Patient } & \multirow[b]{2}{*}{$\operatorname{Sex}$} & \multirow{2}{*}{$\begin{array}{c}\text { Disease } \\
\text { Dunafion (Yaurs) }\end{array}$} & \multirow{2}{*}{$\begin{array}{c}\text { STN-DBS } \\
\text { Duration (Months) }\end{array}$} & \multirow[b]{2}{*}{ LED (mg) } & \multicolumn{4}{|c|}{ STN-DBS Paramelers (Left) } & \multicolumn{4}{|c|}{ STN-DBS Parameters (Pight) } \\
\hline & & & & & v & $\mathrm{Hz}$ & $\mu s$ & Contacts & v & $\mathrm{Hz}$ & $\mu s$ & Contacts \\
\hline 3 & M & 14 & 24 & 300 & 2.4 & 130 & 60 & 2 & 2.1 & 130 & 60 & 6 \\
\hline 4 & $\mathbf{F}$ & 11 & 13 & 250 & 2.2 & 180 & 60 & 1 & 1.8 & 180 & 60 & 10 \\
\hline 5 & M & 5 & 8 & 250 & 2.7 & 130 & 60 & 2 & 2.5 & 130 & 60 & 9 \\
\hline 6 & M & 10 & 6 & 250 & 2.4 & 150 & 60 & 1 & 2.3 & 150 & 60 & 10 \\
\hline 7 & M & 23 & 13 & 350 & 2.6 & 130 & 60 & 2 & 2.6 & 130 & 60 & 11 \\
\hline 9 & M & 7 & 12 & 300 & 2.9 & 130 & 60 & 2 & 3.5 & 130 & 60 & 10 \\
\hline 10 & $\mathbf{F}$ & 12 & 59 & 300 & 3.5 & 130 & 60 & 2 & 2 & 130 & 60 & 7 \\
\hline 12 & M & 13 & 36 & 300 & 2.6 & 130 & 60 & 2 & 2.6 & 130 & 60 & 11 \\
\hline 13 & M & 9 & 12 & 250 & 2.5 & 130 & 60 & 2 & 2.7 & 130 & 60 & 9 \\
\hline 14 & $\mathbf{F}$ & 8 & 11 & 300 & 1.8 & 130 & 60 & 2 & 1.9 & 130 & 60 & 8 \\
\hline 15 & M & 18 & 6 & 350 & 2.5 & 130 & 60 & 1 & 2.7 & 130 & 60 & 11 \\
\hline 16 & $\mathbf{M}$ & 18 & 38 & 200 & 1.5 & 170 & 60 & 1 & 1.7 & 170 & 60 & 8 \\
\hline \multirow[t]{2}{*}{17} & M & 10 & 12 & 350 & 2.5 & 210 & 60 & 2 & 2.3 & 210 & 60 & 8 \\
\hline & $\begin{array}{l}M \\
\pm S D\end{array}$ & $\begin{array}{l}121 \\
\pm 5\end{array}$ & $\begin{array}{r}19.2 \\
\pm 15.9\end{array}$ & $\begin{array}{r}288.5 \\
\pm 46.3\end{array}$ & $\begin{array}{r}2.47 \\
\pm 0.48\end{array}$ & $\begin{array}{l}144.6 \\
\pm 26\end{array}$ & & & $\begin{array}{r}2.36 \\
\pm 0.48\end{array}$ & $\begin{aligned} & 144.6 \\
\pm & \mathbf{2 6}\end{aligned}$ & & \\
\hline
\end{tabular}

Contact: locations of STN-DBS curvent delivery on the four possidie contacts along the electrode (generabor case posifve, ebctrodecontact negafive).

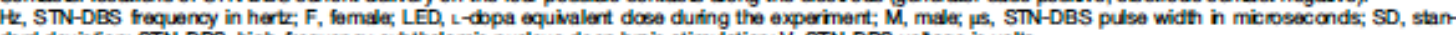
dard deviafort STN-DBS, high-frequency subthalami nudeus deep bain stimulation; V, STN-DBS volage in volts.

Table 1. Clinical data and STN-DBS parameters of the Parkinson's disease patients.

Contacts: locations of STN-DBS current delivery on the 4 possible contacts along the electrode (generator case positive, electrode contact negative); Hz: STN-DBS frequency in hertz; F: female; LED: levodopa equivalent dose during the experiment; M: male; $\mu \mathrm{s:} \mathrm{STN-DBS} \mathrm{pulse} \mathrm{width} \mathrm{in} \mathrm{microseconds;}$ SD: standard deviation; STN-DBS: high frequency subthalamic nucleus deep brain stimulation; V: STNDBS voltage in volts. 
TABLE 2. Demographics and clinical data of the PD patients and healthy controls

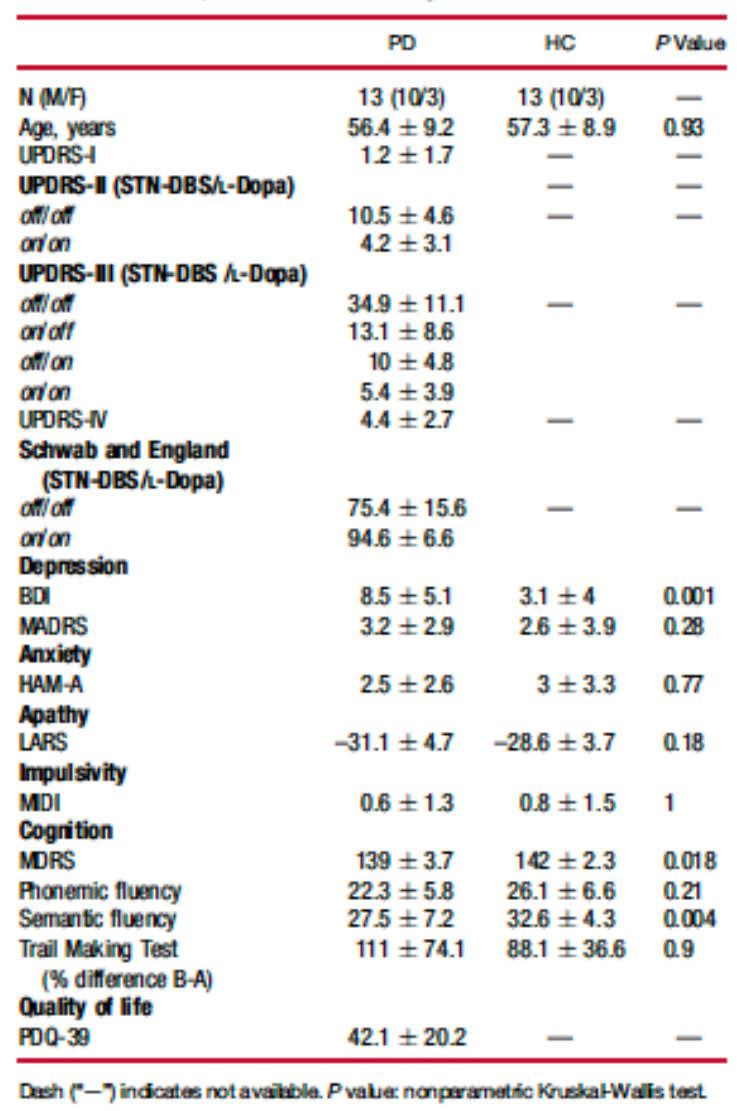

Table 2. Demographics and clinical data of the Parkinson's disease patients and healthy controls.

-: not available; BDI: Beck Depression Inventory; HAM-A: Hamilton Anxiety Rating Scale; LARS: Lille Apathy Rating Scale; MADRS: Montgomery-Asberg Depression Rating Scale; MDRS: Mattis Dementia Rating Scale; MIDI: Minnesota Impulsive Disorders Interview; PDQ-39: Parkinson's Disease Questionnaire - 39; UPDRS: Unified Parkinson's Disease Rating Scale (I: Non-motor aspects of experiences of daily living; II: Motor aspects of experiences of daily living; III: Motor evaluation; IV: Motor complications); p-value: non-parametric Kruskal-Wallis Test. 


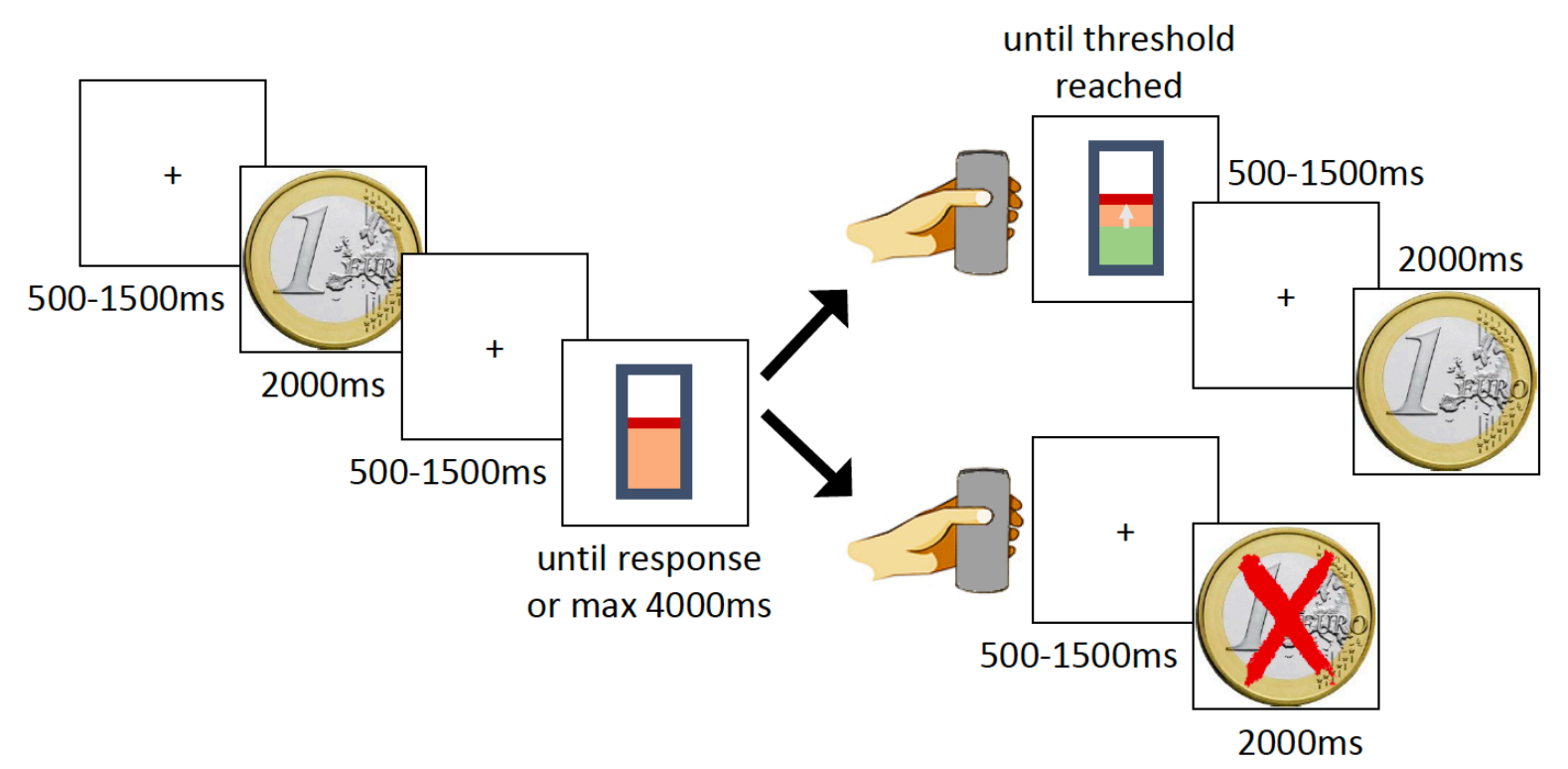

Figure 1. Experimental design of the study. 

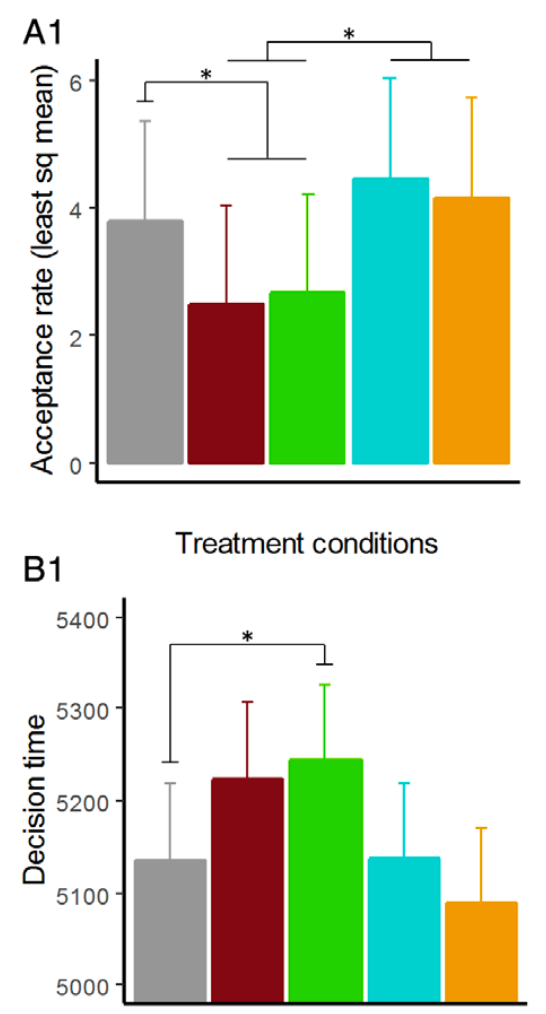

Treatment conditions

C1

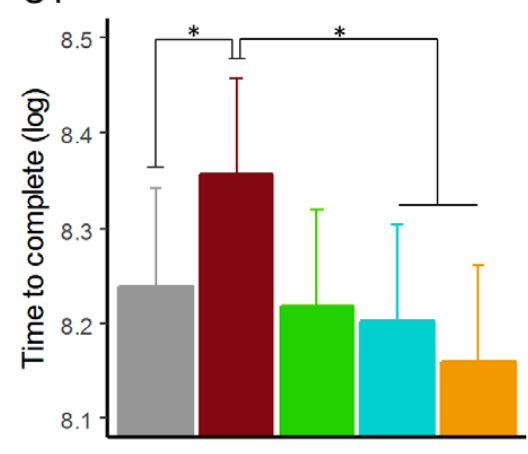

Treatment conditions
A2

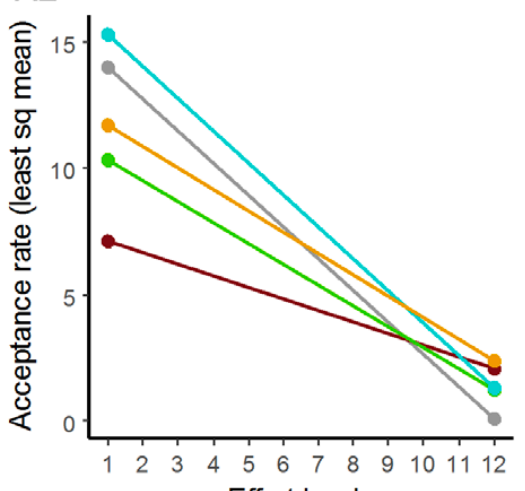

Effort levels

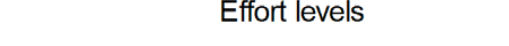

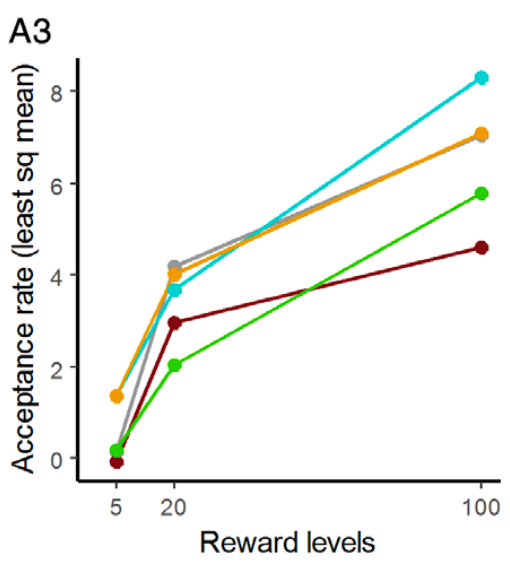
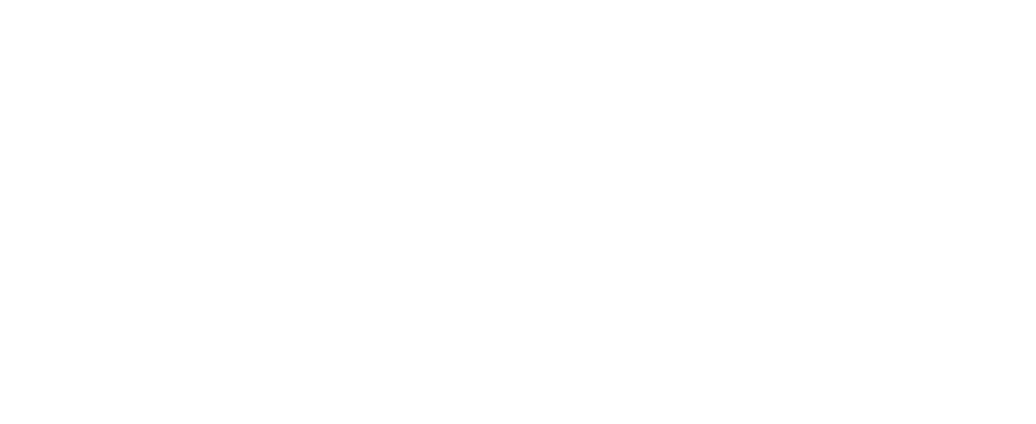

C2

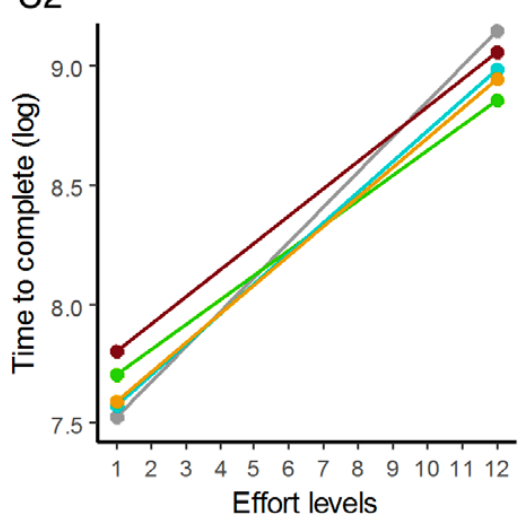

Figure 2. Acceptance rate (least square mean) per treatment (A1), effort required (A2) and reward condition (A3); Decision time (in milliseconds) per treatment (B1); Time to complete trial (log) per treatment (C1) and effort required (C2).

$*$ : p-value $<0.05$ 